\title{
EUS-guided detection and internal drainage of an open pancreaticocutaneous fistula after acute necrotizing pancreatitis
}

Endoscopic ultrasound (EUS)-guided drainage is one of the leading methods for the management of pancreatic fluid collections (PFCs) and fistulas [1,2]. However, it is technically challenging to find a fistula, which is usually smaller than a collection since the fluid discharges spontaneously.

We report the case of a 37-year-old patient with pancreaticocutaneous fistula after acute pancreatitis. First, transpapillary drainage with a plastic stent in the Wirsung duct was attempted, but the pancreatic fistula remained productive and was confirmed by MRI.

Again drainage was attempted, but this time the caudal part of the pancreatic duct was totally excluded and a double pigtail plastic stent was placed between the duodenum and the remaining PFCs ( $\vee$ Video 1, Fig. 1). In a second step, we then tried to puncture the fistula tract through the stomach, but the fistula was too small to be detected by EUS alone. We used a guidewire through the cutaneous orifice of the fistula to find the tract and instilled water and contrast agent through an opacification catheter, but again we could not identify the fistula. We then inflated a 4-mm-diameter dilatation balloon into the fistula tract as close as possible to the pancreas to make it visible on EUS. We punctured the balIoon with a 19-G needle through the gastric wall ( $>$ Fig.2) without managing to explode it, but we succeeded in placing the guidewire in the fistula when we deflated the balloon and retrieved it at the skin orifice. After this, with EUS guidance ensuring the correct position, we used a 10 -Fr cystotome to place a double pigtail plastic stent into the fistula tract ( $\mathbf{F i g . 2}$, - Fig. 3). The cutaneous orifice of the fistula sealed immediately, and this result was still sustained 2 months later.

A balloon can be used as a landmark to help the endoscopist detect a small fistula tract in which he or she wishes to place a transgastric drain.

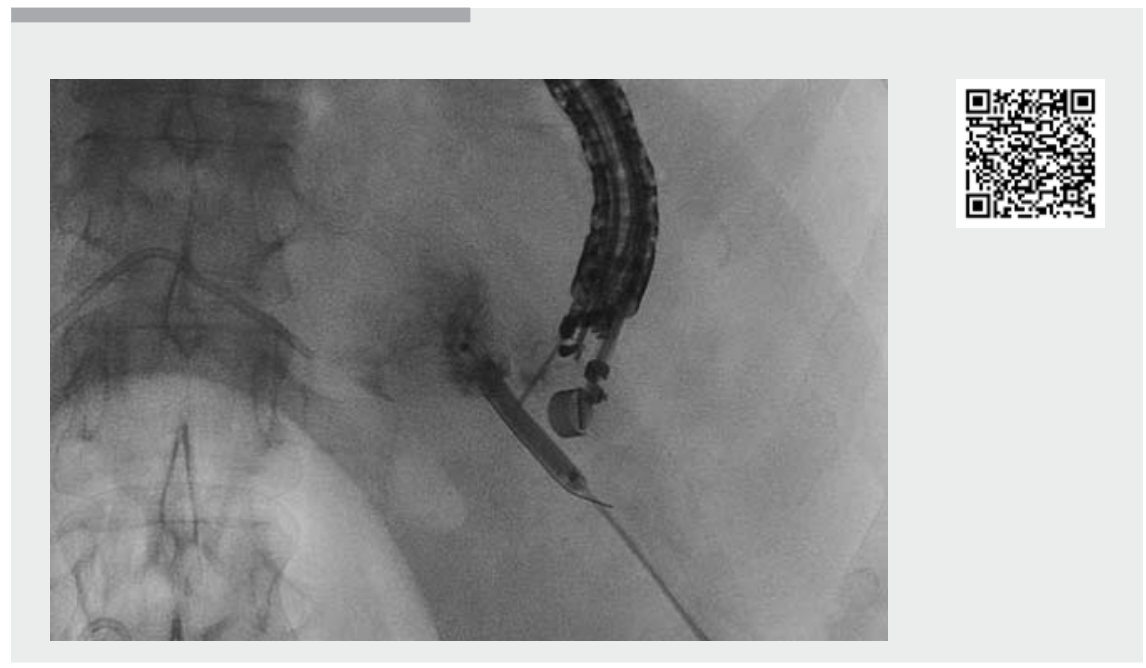

Video 1 Procedure of drainage guided by EUS and using a balloon as a landmark.

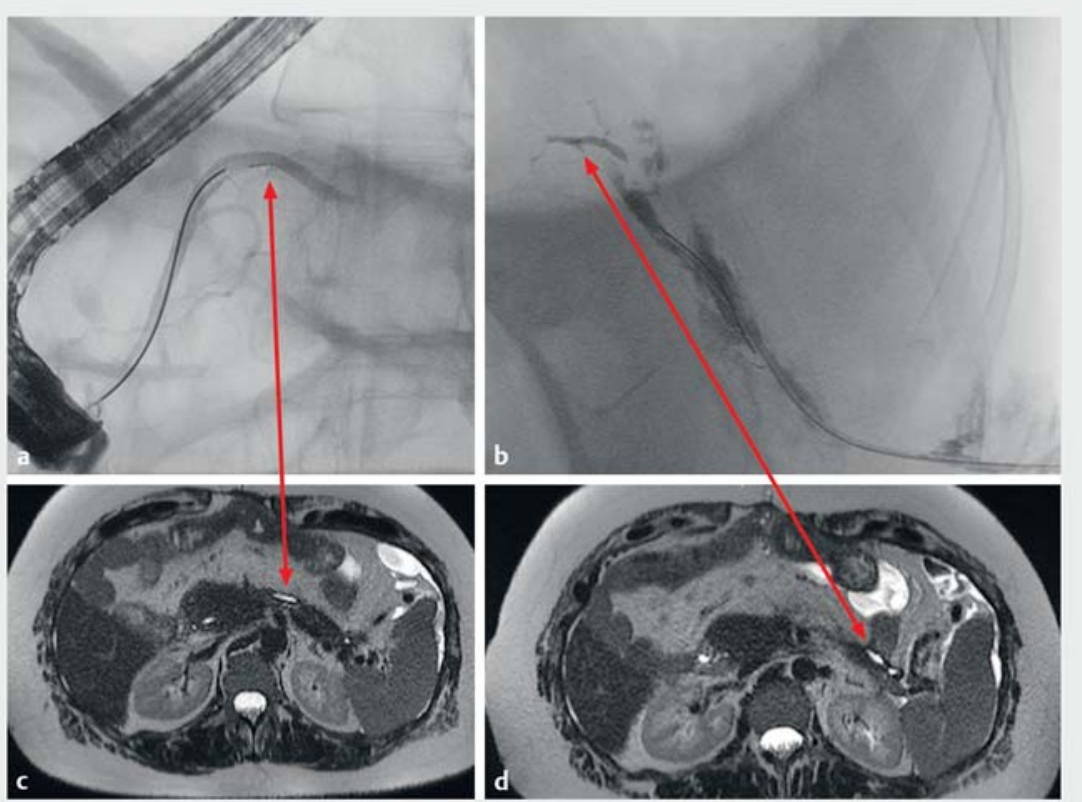

- Fig. $1 \mathrm{MRI}$ and radioscopic appearance of the collection and fistula. a Cephalic portion of the Wirsung duct seen during the EUS-guided procedure. $\mathbf{b}$ Distal excluded portion of the Wirsung duct opacified via the cutaneous fistula during the EUS-guided procedure. c Cephalic portion of the Wirsung duct seen with MRI. $\mathbf{d}$ Distal excluded portion of the Wirsung duct seen with MRI. 

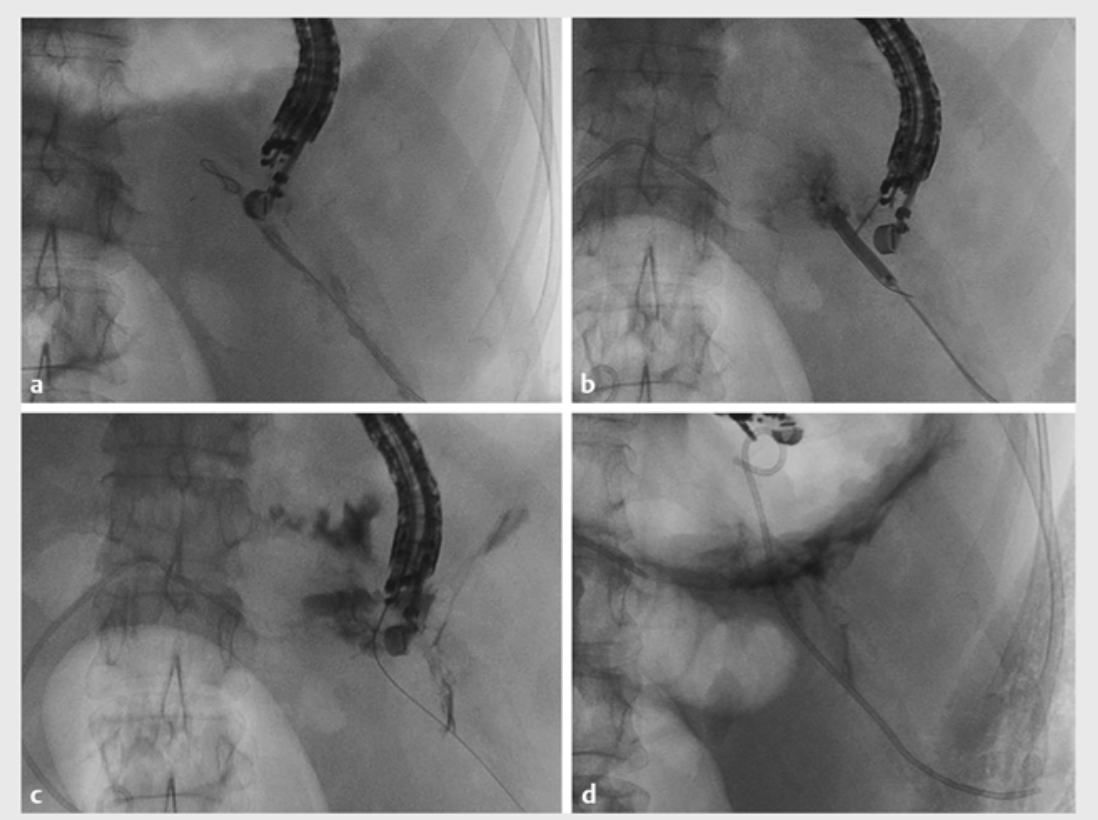

- Fig. 2 Radioscopic appearance of the fistula drain. a Guidewire introduced via the cutaneous orifice with opacification. $\mathbf{b}$ Inflation of the balloon to make an EUS landmark, because the tract was not detectable with water instillation in the fistula. $\mathbf{c}$ Insertion of the guidewire into the fistula after balloon deflation. $\mathbf{d}$ Stent placement.

Endoscopy_UCTN_Code_TTT_1AS_2AG

Competing interests

The authors declare that they have no conflict of interest.

The authors

Armelle Schoch ${ }^{1}$, Jérôme Rivory ${ }^{1}$, Olivier Monneuse $^{2}$, Nada Nargues ${ }^{3}$, Thierry Ponchon ${ }^{1}$, Mathieu Pioche ${ }^{1}$

1 Department of Endoscopy and Gastroenterology, Pavillon L, Edouard Herriot Hospital, Lyon, France

2 Department of Digestive Surgery, Edouard Herriot Hospital, Lyon, France

3 Department of Anesthesia, Pavillon F, Edouard Herriot Hospital, Lyon, France

\section{Corresponding author}

\section{Armelle Schoch, MD}

Department of Gastroenterology, Edouard Herriot Hospital, Place d'Arsonval, Lyon 69008, France

Fax: +33-4-72684691

armelle.schoch@chu-lyon.fr

\section{References}

[1] Alali A, Mosko J, May G et al. Endoscopic Ultrasound-Guided Management of Pancreatic Fluid Collections: Update and Review of the Literature. Clin Endosc 2017; 50: 117125

[2] Jürgensen C, Distler M, Arlt A et al. EUSguided drainage in the management of postoperative pancreatic leaks and fistulas (with video). Gastrointest Endosc 2019; 89: 311-319.e1

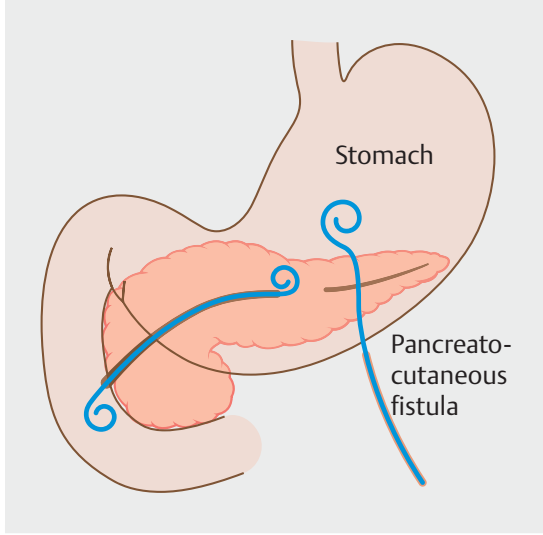

- Fig. 3 Schematic representation of the final drainage of both the Wirsung duct and the fistula tract.

\section{Bibliography}

DOI https://doi.org/10.1055/a-1099-8998

Published online: 12.2.2020

Endoscopy 2020; 52: E284-E285

(c) Georg Thieme Verlag KG

Stuttgart · New York

ISSN 0013-726X

\section{ENDOSCOPY E-VIDEOS}

https://eref.thieme.de/e-videos

口回 Endoscopy E-Videos is a free access online section, reporting 靣程: on interesting cases and new techniques in gastroenterological endoscopy. All papers include a high quality video and all contributions are freely accessible online.

This section has its own submission website at https://mc.manuscriptcentral.com/e-videos 